ARTICLE

\title{
Atomically isolated nickel species anchored on graphitized carbon for efficient hydrogen evolution electrocatalysis
}

Lili Fan ${ }^{1,2, \star}$, Peng Fei Liu ${ }^{3, \star}$, Xuecheng Yan ${ }^{1}$, Lin Gu${ }^{4}$, Zhen Zhong Yang ${ }^{4}$, Hua Gui Yang ${ }^{3}$, Shilun Qiu ${ }^{2} \&$ Xiangdong Yao ${ }^{1}$

Hydrogen production through electrochemical process is at the heart of key renewable energy technologies including water splitting and hydrogen fuel cells. Despite tremendous efforts, exploring cheap, efficient and durable electrocatalysts for hydrogen evolution still remains as a great challenge. Here we synthesize a nickel-carbon-based catalyst, from carbonization of metal-organic frameworks, to replace currently best-known platinum-based materials for electrocatalytic hydrogen evolution. This nickel-carbon-based catalyst can be activated to obtain isolated nickel atoms on the graphitic carbon support when applying electrochemical potential, exhibiting highly efficient hydrogen evolution performance with high exchange current density of $1.2 \mathrm{mAcm}^{-2}$ and impressive durability. This work may enable new opportunities for designing and tuning properties of electrocatalysts at atomic scale for largescale water electrolysis.

\footnotetext{
${ }^{1}$ School of Natural Sciences, Queensland Micro- and Nanotechnology Centre, Griffith University, Brisbane, QLD 4111, Australia. ${ }^{2}$ State Key Laboratory of Inorganic Synthesis and Preparative Chemistry, College of Chemistry, Jilin University, Changchun 130012, China. ${ }^{3}$ Key Laboratory for Ultrafine Materials of Ministry of Education, School of Materials Science and Engineering, East China University of Science and Technology, Shanghai 200237, China. ${ }^{4}$ Institute of Physics, Beijing National Laboratory for Condensed Matter Physics, Chinese Academy of Sciences, Beijing 100190, China. * These authors contributed equally to this work. Correspondence and requests for materials should be addressed to H.G.Y. (email: hgyang@ecust.edu.cn) or to S.Q. (email: sqiu@jlu.edu.cn) or to X.Y. (email: x.yao@griffith.edu.au).
} 
$\mathrm{M}$ olecular hydrogen $\left(\mathrm{H}_{2}\right)$, when generated from carbonneutral processes, plays a vital role in the sustainable energy systems and chemical industry ${ }^{1-3}$. Electrolysis has stood out among various hydrogen production technologies because of high energy-conversion efficiency and environmentally benign process, especially coupled with energy sources such as solar and wind ${ }^{4-6}$. In this rapidly developed field, finding active catalysts for hydrogen evolution reaction (HER) to lower large potentials is of paramount importance to promote water electrolysis application. It has been confirmed that platinum $(\mathrm{Pt})$ is the most active and stable electrocatalyst for HER, with only small overpotentials for high reaction rate. However, its low abundance and consequently high cost limit its large-scale commercial applications. Hence, exploring cheap, efficient and durable alternatives of $\mathrm{Pt}$ is crucial to facilitate the global scalability of such potential clean-energy technology ${ }^{7}$. Therefore, a series of Pt-free electrocatalysts have been identified for HER in strong acids, such as metal compounds ${ }^{8-17}$ (sulfides, nitrides, carbides, borides and phosphides) and carbon-based materials ${ }^{18-20}$. Moreover, remarkable advances in nanostructuring or stabilizing these electrocatalysts on carbon substrates have further exposed more active sites simultaneously with enhanced electrical conductivity ${ }^{21-27}$. Recently, design strategies like encapsulating $3 \mathrm{~d}$ transition metals into carbon nanotubes and graphene nanoshells have been reported to improve the longterm activity $28-30$. Even so, compared with Pt, these reported materials show dwarfed in activity and durability.

Isolated metal atoms, owing to their low-coordination and unsaturated atoms functioned as active sites, have been demonstrated more catalytic active than nanometer-sized metal particles ${ }^{31-35}$. Supported isolated noble metals, such as palladium, Pt and gold, have been reported as highly active catalysts for hydrogenation reactions, $\mathrm{CO}$ oxidation reactions and water-gas shift reactions ${ }^{33-35}$. However, earth-abundant $3 \mathrm{~d}$ transition metals, which have been investigated as promising alternatives in alkaline electrolytes ${ }^{36,37}$, have not been downsized to single atoms to improve their activity for HER so far.

Herein, we show a nickel-carbon (Ni-C)-based catalyst, which can be tuned by electrochemical methods to obtain atomically isolated $\mathrm{Ni}$ species anchored on graphitized carbon, consequently displaying high activity and durability for HER. The activated$\mathrm{Ni}-\mathrm{Carbon}$ (A-Ni-C) catalyst exhibts overpotential for the current density of $10 \mathrm{~mA} \mathrm{~cm}^{-2}, 20 \mathrm{~mA} \mathrm{~cm}^{-2}$ and $100 \mathrm{~mA} \mathrm{~cm}^{-2}$ at $-34 \mathrm{mV},-48 \mathrm{mV}$ and $-112 \mathrm{mV}$, respectively, a low Tafel slope of $41 \mathrm{mV}$ per decade and a large exchange current density of $1.2 \mathrm{~mA} \mathrm{~cm}^{-2}$. More importantly, A-Ni-C could maintain high activity for $>25 \mathrm{~h}$ in the chronoamperometric test. A variety of analytical techniques illustrate that $\mathrm{Ni}$ single atoms formed during the activation process, which could contribute greatly to HER performance. Compared with Pt and other Pt alternatives, $\mathrm{A}-\mathrm{Ni}-\mathrm{C}$ is composed of more abundant elements in the earth's crust. These findings in our work may help accelerate the largescale application of proton exchange membrane (PEM) electrolysers and solar photoelectrochemical (PEC) water electrolysers.

\section{Results}

Sythesis and characteration of A-Ni-C catalyst. A-Ni-C catalyst was obtained from well-dispersed $\mathrm{Ni}$ metal in the graphitized carbon matrix. The synthesized Ni-based metal-organic framework (Ni-MOF) was used as the precursor (Fig. 1). Followed by carbonization at $700{ }^{\circ} \mathrm{C}$ in nitrogen $\left(\mathrm{N}_{2}\right)$ atmosphere, Ni nanoparticles encapsulated in graphene layers $(\mathrm{Ni} @ \mathrm{C})$ were prepared. Hydrochloric acid $(\mathrm{HCl})$ leaching treatment was used to remove the redundant $\mathrm{Ni}$ metal ( $\mathrm{HCl}-\mathrm{Ni} @ \mathrm{C})$. After $\mathrm{HCl}$ treatment, hollow onion-like carbon nanoshells along with little $\mathrm{Ni}$

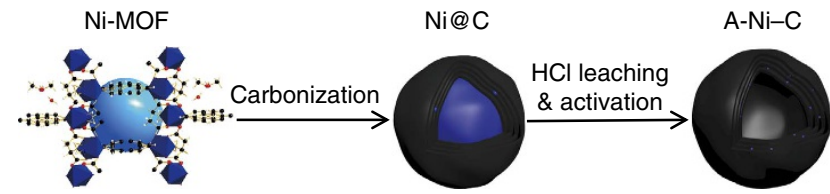

Figure 1 | Schematic diagram of synthesis and activation process of the Ni-C catalysts. The Ni-MOF used as a precursor consists of an orthorhombic crystal. Atoms are shown as follows: $\mathrm{C}$, black; $\mathrm{H}$, white; $\mathrm{O}$, red; $\mathrm{N}$, blue; $\mathrm{Ni}$, royal blue. Carbonization of the synthesized Ni-MOF was at $700^{\circ} \mathrm{C}$ in $\mathrm{N}_{2}$ atmosphere to obtain $\mathrm{Ni@C.} \mathrm{HCl}$ leaching treatment was repeated three times to sufficiently dissolve exposed Ni metal. Constant potential and $\mathrm{CV}$ treatments were performed to activate the catalysts until they reached the optimal performance and remained stable. During the activation process, Ni single atoms formed in situ anchored on the graphitized carbon.

nanoparticles protected by graphene layers remained. We then applied electrochemical cyclic-potential on the $\mathrm{HCl}-\mathrm{Ni} @ \mathrm{C}$ catalysts-decorated electrode, unexpected activation process was observed. Similar activation processes were also reported in the literature ${ }^{13,20}$. To our surprise, direct constant potential on Ni@C can also activate the electrocatalyst, which was conducted until the electrocatalyst reached the optimized and stable activity. We found $\mathrm{Ni}$ single atoms formed during all these activation process, which is verified as discussed later.

The nanostructure of Ni@C was characterized by a transmission electron microscope (TEM). Low-magnification TEM image of Ni@C displays Ni metal inside carbon nanospheres (Supplementary Fig. 1a). The size distribution image (Supplementary Fig. 1b) suggests that the nanospheres have an average size around $10 \mathrm{~nm}$. After $\mathrm{HCl}$ leaching, the high-resolution TEM image of HCl-Ni@C shows hollow onion-like nanoshells along with little Ni metal aggregates encapsulated in the graphene layers (Fig. 2a). To further study the structure changes of the catalyst before and after activation, a JEM-ARM200F scanning TEM (STEM) fitted with a double aberration-corrector for both probeforming and the imaging lenses was used. In the STEM image of $\mathrm{HCl}-\mathrm{Ni} @ \mathrm{C}$, the measured Ni (111) d-spacing $(0.204 \mathrm{~nm})$ and $\mathrm{Ni}(200) \mathrm{d}$-spacing $(0.176 \mathrm{~nm})$ again confirm the existence of well crystalline $\mathrm{Ni}$ metal in the graphitic carbon nanoshells (inset of Fig. 2a). The thickness of graphene layer is uneven with exposure of Ni nanoparticles, which would provide possibilities for slow dissolution of $\mathrm{Ni}$ metal during the activation process in the acidic solution. The bright-field STEM image of A-Ni-C (Supplementary Fig. 2) illustrates that the measured (002) d-spacing of the graphitic carbon ranges from about 0.33 to $0.36 \mathrm{~nm}$, indicating the carbon structure is somewhat disordered, rather than ideally graphitic, which was also evidenced by the X-ray diffraction (XRD) and Raman analysis. Individual metal atoms in practical catalysts can be discerned in the atomic resolution high-angle annular dark-field (HAADF) images ${ }^{33-35}$ For the sample A-Ni-C, the atomically isolated $\mathrm{Ni}$ species (marked by white circles) are dispersed on the partially graphitized carbon matrix (Fig. 2b). Examination of different regions (Supplementary Fig. 2) confirms abundance of Ni single atoms present in A-Ni-C. Considering that the elements of N, F and $\mathrm{S}$ have a smaller atomic number than $\mathrm{Ni}$, these impuries can hardly exsit as bright tiny spots in the metal-carbon system. HAADF images of controled samples have also ruled out this possiblity (Supplementary Fig. 3). About $78 \%$ of the $\mathrm{Ni}$ species counted in the images were present as single atoms away from each other (inset of Fig. 2b). A minority of subnanometer $\mathrm{Ni}$ clusters present in the same sample did not have the packed Ni atom structure of Ni nanoparticles. 

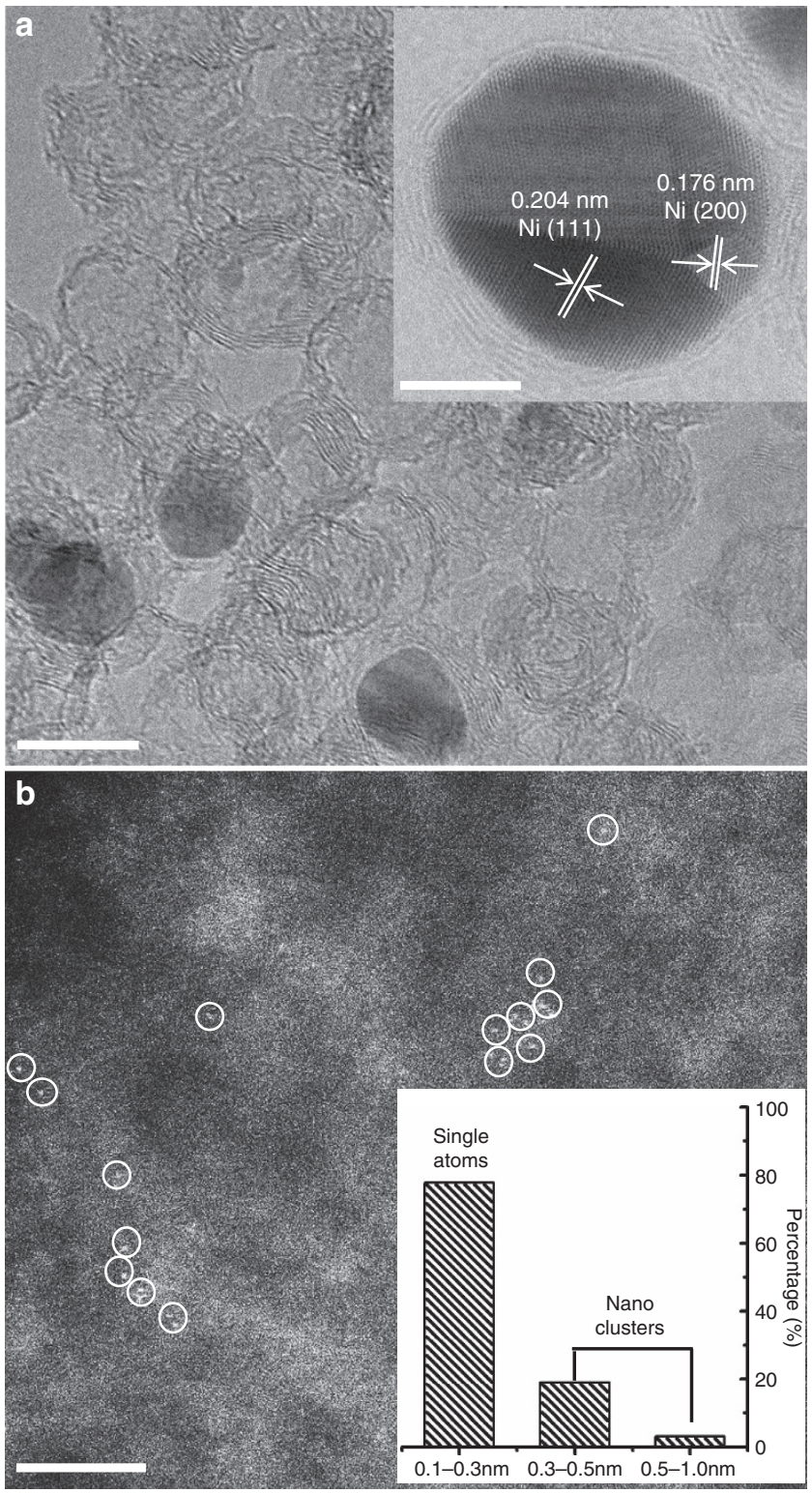

Figure 2 | Micrographs of samples HCl-Ni@C and A-Ni-C. (a) HRTEM image of HCl-Ni@C. Scale bar, 10 nm. Inset of a, BF STEM image of Ni metal encapsulated in graphene layers. Scale bar, $5 \mathrm{~nm}$. The area of graphene with exposure of $\mathrm{Ni}$ nanoparticle provides the opportunity that $\mathrm{Ni}$ metal would slowly resolve during the activation process. (b) Subångström resolution HAADF STEM image of A-Ni-C. The circles are drawn around isolated $\mathrm{Ni}$ atoms. Scale bar, $3 \mathrm{~nm}$. Inset of $\mathbf{b}$, the size distribution figure, which is based on $>120$ observed $\mathrm{Ni}$ species counted from high-magnification images (recorded at $4 \times$ original magnification).

The multiple peaks on the XRD pattern of the synthesized Ni-MOF (Supplementary Fig. 4a) well match those of the typical crystalline structure of $\left[\mathrm{Ni}_{2}(\mathrm{~L}-\mathrm{asp})_{2}(\mathrm{bpy})\right] \bullet \mathrm{CH}_{3} \mathrm{OH} \bullet \mathrm{H}_{2} \mathrm{O}$. $\mathrm{Ni} @ \mathrm{C}$ exhibits the cubic phase of Ni metal (JSPDS NO. 04-0850) with a broad shoulder peak in the range $20-30^{\circ}(2 \theta)$, which originates from the partially graphitized carbon specie (Fig. 3a). The diffraction peaks of graphitic carbon become higher and sharper with the increased temperature (Supplementary Fig. 4b). Raman spectrum of Ni@C (Fig. 3b) further confirms that the Ni-MOF is partially graphitized at $700^{\circ} \mathrm{C}$. Among carbon-based catalysts, these graphitic carbon structures formed during the carbonization treatment may significantly enhance the electronic conductivity
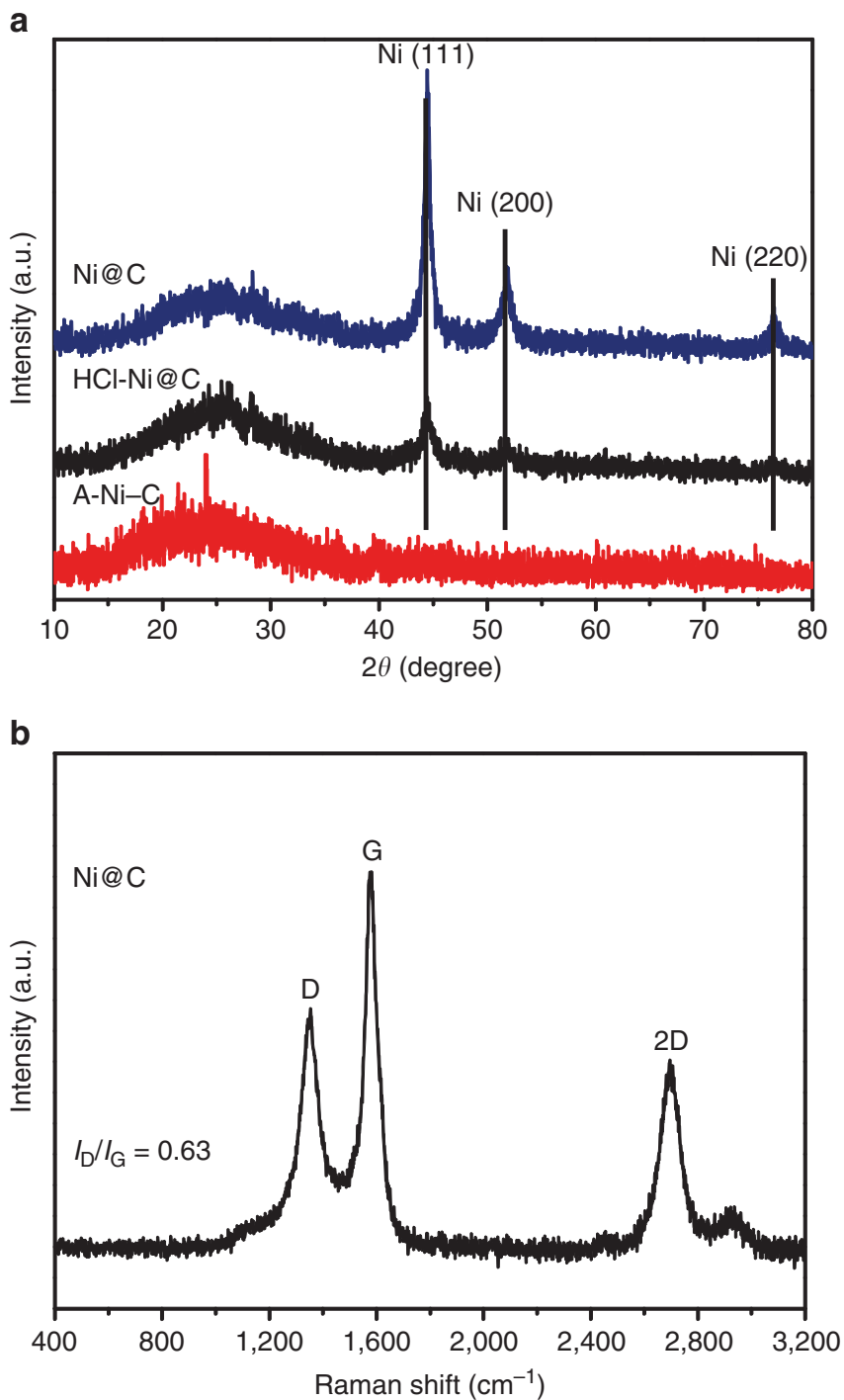

Figure 3 | Structure characterization of the Ni-C catalysts. (a) XRD patterns of $\mathrm{Ni@C,HCl-Ni@C} \mathrm{and} \mathrm{A}-\mathrm{Ni}-\mathrm{C}$, respectively. The diffraction peaks of $\mathrm{Ni}$ in $\mathrm{Ni@C}$ and $\mathrm{HCl}-\mathrm{Ni} @ \mathrm{C}$ confirm the existence of well crystalline $\mathrm{Ni}$ metal. The red line corresponding to $\mathrm{A}-\mathrm{Ni}-\mathrm{C}$ illustrates that no $\mathrm{Ni}$-Containing crystal phase was detected after activation process. (b) Raman spectrum of $\mathrm{Ni@C}$ with $I_{\mathrm{D}} / I_{\mathrm{G}}=0.63$, indicating the partial graphitization at $700^{\circ} \mathrm{C}$.

and corrosion resistance, which would improve the electrocatalytic efficiency ${ }^{29}$. After sufficiently washed by $\mathrm{HCl}$, little $\mathrm{Ni}$ nanoparticles encapsulated in the multi graphene layers remained. The XRD pattern of $\mathrm{HCl}-\mathrm{Ni} @ \mathrm{C}$ proves the existence of the $\mathrm{Ni}$ metal. However, no Ni-Containing signal was detected in the sample A-Ni-C, primarily attributed to insensitivity of $\mathrm{XRD}$ to single atoms or small clusters.

The binding state was investigated by X-ray photoelectron spectroscopy (XPS). As shown in Supplementary Fig. 5, N-C bonds in the samples of $\mathrm{Ni@C,HCl-Ni@C} \mathrm{and} \mathrm{A}-\mathrm{Ni}-\mathrm{C}$ are in the form of pyridine $(398.9 \mathrm{eV})$, pyrrole $(400.4 \mathrm{eV})$ and graphite $(401.3 \mathrm{eV})$ (refs 28,38). The quantitative analysis of the XPS results reveals that the atomic ratios of N/C in Ni@C, HCl-Ni@C and $\mathrm{A}-\mathrm{Ni}-\mathrm{C}$ are 4.62:100, 3.80:100 and 2.21:100, respectively. The existence of $\mathrm{N}$ dopants in the $\mathrm{A}-\mathrm{Ni}-\mathrm{C}$ would inherently increase the ability of interacting with reactants and render high positive charge density on their adjacent carbon atoms, which could also 
contribute to the high activity of A-Ni-C samples ${ }^{28,29}$. The Ni $2 \mathrm{p}$ XPS spectrum of Ni@C reveals the coexistence of $\mathrm{Ni}^{0}(852.8 \mathrm{eV})$ and $\mathrm{Ni}^{2}+(853.7 \mathrm{eV})$, which can be ascribed to $\mathrm{Ni}-\mathrm{Ni}$ and $\mathrm{Ni}-\mathrm{O}$ bonding ${ }^{39,40}$ (Fig. 4a). After $\mathrm{HCl}$ leaching, the $\mathrm{Ni} 2 \mathrm{p}$ XPS spectrum of HCl-Ni@C nearly remains the same as that of $\mathrm{Ni@C}$, suggesting the residue of $\mathrm{Ni}$ metal. The existence of $\mathrm{Ni}-\mathrm{O}$ bonding can be attributed to the slow oxidation of the exposed Ni metal ${ }^{41-}$ 43. We further collected samples of A-Ni-C for analysis. The XPS analysis of A-Ni-C (Supplementary Fig. 6, Supplementary Table 1) illustrates it contains $\mathrm{Ni}, \mathrm{C}, \mathrm{N}, \mathrm{F}, \mathrm{S}$ and $\mathrm{O}$ elements without any Pt impurity, eliminating the influence of Pt for HER performance. We should point out that $\mathrm{F}, \mathrm{S}$ and $\mathrm{O}$ elements mainly resulted from the Nafion solution. To confirm that trace amount of $\mathrm{Ni}$ in the $\mathrm{A}-\mathrm{Ni}-\mathrm{C}$ sample contributes to the HER activity, we determined the $\mathrm{Ni}$ contents by indicatively coupled plasma atomic emission spectroscopy. As shown in Supplementary Table 2, the weight ratios of Ni in the Ni@C, $\mathrm{HCl}$ $\mathrm{Ni@C}$ and A-Ni-C were 85.0\%, 5.3\% and 1.5\%, respectively. We found that the $\mathrm{Ni}$ content decreased during the $\mathrm{CV}$ activation process. What is more, no detectable Pt impurities were found in all these samples. In addition, the Ni $2 \mathrm{p}$ XPS spectrum of A-Ni-C (Fig. $4 \mathrm{~b}$ ) has a sharp peak $\sim 860.7 \mathrm{eV}$, which can be associated with the strong $\mathrm{Ni}-\mathrm{F}$ binding. Specifically, the peak at $852.8 \mathrm{eV}$ is assigned to $\mathrm{Ni}^{0}$, reflecting $\mathrm{Ni}-\mathrm{Ni}$ binding of the Ni clusters.
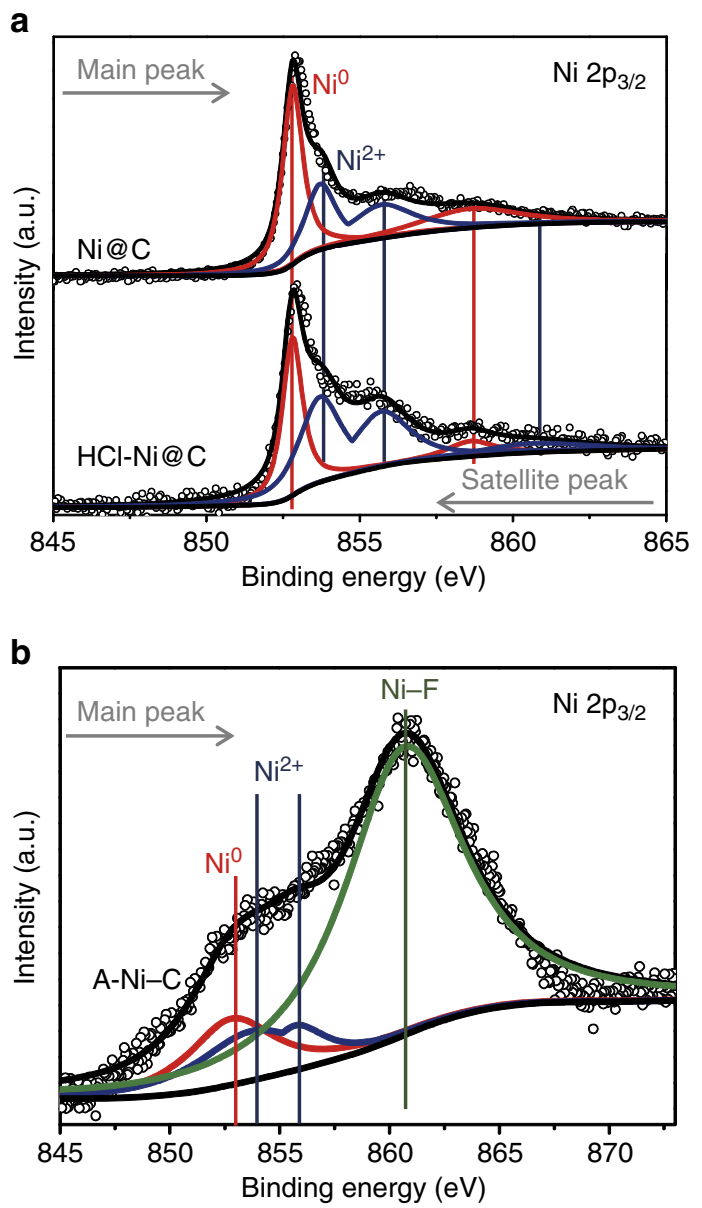

Figure 4 | XPS spectra of the Ni-C catalysts. (a) XPS spectra of Ni $2 p$ peaks of Ni@C and $\mathrm{HCl}-\mathrm{Ni} @ \mathrm{C}$. (b) XPS spectrum of Ni 2p peaks of A-Ni-C. The peaks at $852.8 \mathrm{eV}$ and $853.7 \mathrm{eV}$ are assigned to $\mathrm{Ni}^{\mathrm{O}}$ and $\mathrm{Ni}^{2+}$, respectively. The sharp peak at $860.7 \mathrm{eV}$ can be correlated with $\mathrm{Ni}-\mathrm{F}$ binding, and the element $\mathrm{F}$ comes from Nafion solution.
Electrocatalytic HER activity evaluation. The HER electrocatalytic activity was evaluated in $0.5 \mathrm{M} \mathrm{H}_{2} \mathrm{SO}_{4}$ using a typical three-electrode set-up. All tests were performed without $i R$ compensation. The lineal sweep voltammetry (LSV) curves showing the normalized current density $(j)$ versus voltage $(j$ versus $V$ ) for $\mathrm{A}-\mathrm{Ni}-\mathrm{C}$ and $\mathrm{HCl}-\mathrm{Ni} @ \mathrm{C}$ along with commercial $\mathrm{Pt} / \mathrm{C}$ (5 wt\% Pt on Vulcan carbon black), for comparison, are show in Fig. 5a. As expected, Pt/C catalyst exhibits excellent HER performance. HCl-Ni@C requires overpotential $(\eta)$ of about $-440 \mathrm{mV}$ to reach $j$ of $10 \mathrm{~mA} \mathrm{~cm}^{-2}$. In sharp contrast, A-Ni-C produces $j$ of $10 \mathrm{~mA} \mathrm{~cm}^{-2}, 20 \mathrm{~mA} \mathrm{~cm}^{-2}$ and $100 \mathrm{mAcm}^{-2}$ at $\eta$ of $-34 \mathrm{mV},-48 \mathrm{mV}$ and $-112 \mathrm{mV}$, respectively. These overpotentials are the lowest among the reported acid-stable and earthabundant HER electrocatalysts, including recently reported $\mathrm{Ni}_{2} \mathrm{P}^{14}$, $\mathrm{MoP} \mid \mathrm{S}^{16}, \mathrm{FeP}^{17}, \mathrm{MoS}_{2}$ (refs 8,22,24), $\mathrm{WS}_{2}$ (refs 21,23,25), $\mathrm{Mo}_{2} \mathrm{C}$ (refs 12,13) and chemically doped grapheme-based materials ${ }^{18-20}$ (more details in Supplementary Table 3).

To understand the detailed underlying mechanism of HER activity, Tafel plots based on LSV curves were acquired (Fig. 5b). The linear regions of Tafel plots were fit to the Tafel equation $(\eta=b \log j+a$, where $b$ is the Tafel slope), yielding Tafel slopes of $\sim 34,41,194 \mathrm{mV}$ per decade for $\mathrm{Pt} / \mathrm{C}, \mathrm{A}-\mathrm{Ni}-\mathrm{C}$ and $\mathrm{HCl}-\mathrm{Ni} @ \mathrm{C}$, respectively. The value for $\mathrm{A}-\mathrm{Ni}-\mathrm{C}$ does not correspond to one of the standard HER Tafel slopes $(29,38$, $116 \mathrm{mV}$ per decade), indicating the HER occurs through a Volmer-Heyrovsky mechanism and electrochemical recombination with an additional proton is the rate-limiting step ${ }^{28}$. Moreover, the exchange current density $\left(j_{0}\right)$ was obtained by extrapolation of Tafel plots (Supplementary Fig. 7). The $j_{0}$ of $\mathrm{A}-\mathrm{Ni}-\mathrm{C}$ is about $1.2 \mathrm{~mA} \mathrm{~cm}^{-2}$ (the same magnitude as the value of $2.5 \mathrm{~mA} \mathrm{~cm}^{-2}$ for $\mathrm{Pt} / \mathrm{C}$ ), also highlighting the exceptional $\mathrm{H}_{2}$ evolving efficiency of $\mathrm{A}-\mathrm{Ni}-\mathrm{C}$ catalyst.

The optimal activity of $\mathrm{A}-\mathrm{Ni}-\mathrm{C}$ catalyst would also be attributed to strong chemical and electronic coupling between graphitized carbon and $\mathrm{Ni}$ single atoms, permitting highly efficient electrical communication between the catalytic active sites and the underlying electrode substrate. Electrochemical impedance spectroscopy measurements were performed to confirm the hypothesis (Fig. 5c). The charge transfer resistance of $\mathrm{A}-\mathrm{Ni}-\mathrm{C}$ is similar to that of $\mathrm{Pt} / \mathrm{C}$, which is much lower than that of HCl-Ni@C. Thus, much faster electron transfer between the catalytic active sites of $\mathrm{A}-\mathrm{Ni}-\mathrm{C}$ and the electrode substrate is one of the key factors contributing to the superior HER kinetics.

Durability of A-Ni-C catalyst. The durability is a key concern of all catalysts. In this study, accelerated degradation measurements were adopted to evaluate the durability. Cyclic voltammetric (CV) sweeps between $+905 \mathrm{mV}$ and $-95 \mathrm{mV}$ versus the reversible hydrogen electrode potential (versus RHE) at $100 \mathrm{mV} \mathrm{s}^{-1}$ were applied to HCl-Ni@C-decorated glassy carbon (GC) electrode. Post-potential-cycling LSV curves were recorded (Supplementary Fig. 8). HER performance after 8,000 cycles retained almost the same to the test after 4,000 cycles. To further probe the durability of $\mathrm{A}-\mathrm{Ni}-\mathrm{C}$ in the acidic environment, continuous HER at a static overpotential was conducted (Fig. 5d). When operating a constant overpotential of $-45 \mathrm{mV}$, a continuous HER process occurred to generate molecular $\mathrm{H}_{2}$ (different overpotentials were applied to generate $\mathrm{H}_{2}$ shown in Supplementary Movie 1). During the first $11 \mathrm{~h}$, the current density of $\sim 10 \mathrm{~mA} \mathrm{~cm}^{-2}$ was observed, and then gradually increased to $\sim 14 \mathrm{~mA} \mathrm{~cm}^{-2}$, which might be caused by adequate activation of the catalyst. In addition, the current density levelled out at $\sim 12 \mathrm{~mA} \mathrm{~cm}^{-2}$. It should be mentioned that the high activity was maintained for $>25 \mathrm{~h}$ in the chronoamperometric electrolysis (after CV activation, $\geq 4,000$ 
a

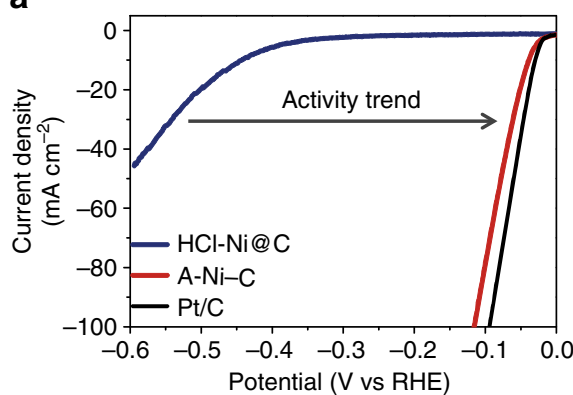

C

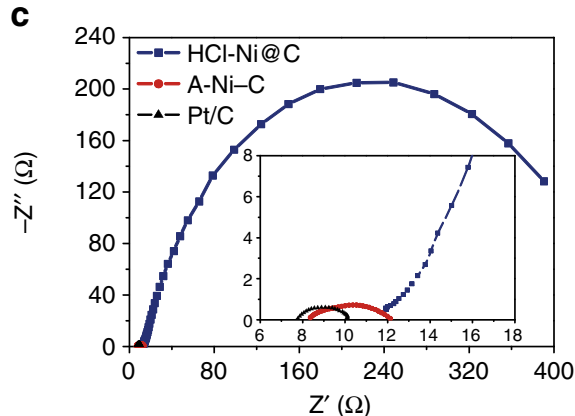

b

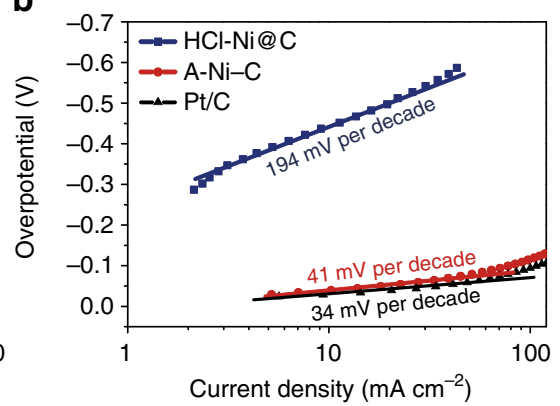

d

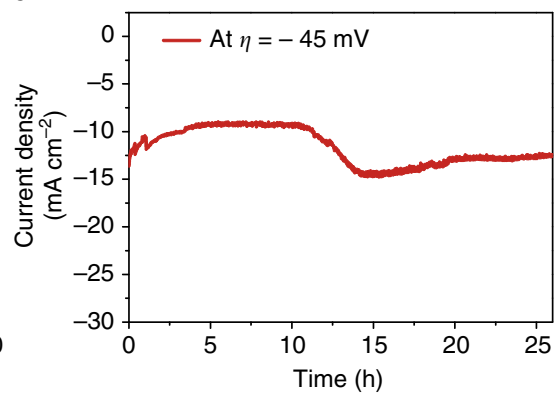

Figure 5 | HER electrocatalytic properties of the Ni-C catalysts. (a) LSV curves of HCl-Ni@C, A-Ni-C and Pt/C. (b) Tafel plots obtained from LSV curves in $\mathbf{a}$, indicating significant improvement in activity for HER after activation. (c) EIS spectra of HCl-Ni@C, A-Ni-C and Pt/C at the overpotential of $-100 \mathrm{mV}$. Inset of $\mathbf{c}$ represents a close-up view of the spectra at high frequencies. A-Ni-C-modified GC electrode displays much lower impedance than $\mathrm{HCl}-\mathrm{Ni} @ \mathrm{C}$ modified GC electrode, similar to that of Pt/C-modified GC electrode. (d) Chronoamperometric curve of A-Ni-C at $\eta=-45 \mathrm{mV}$, revealing nearly no apparent deactivation after $25 \mathrm{~h}$. Note: all the electrochemical data of A-Ni-C catalysts were obtained after electrochemical cyclic-potential activation.

a
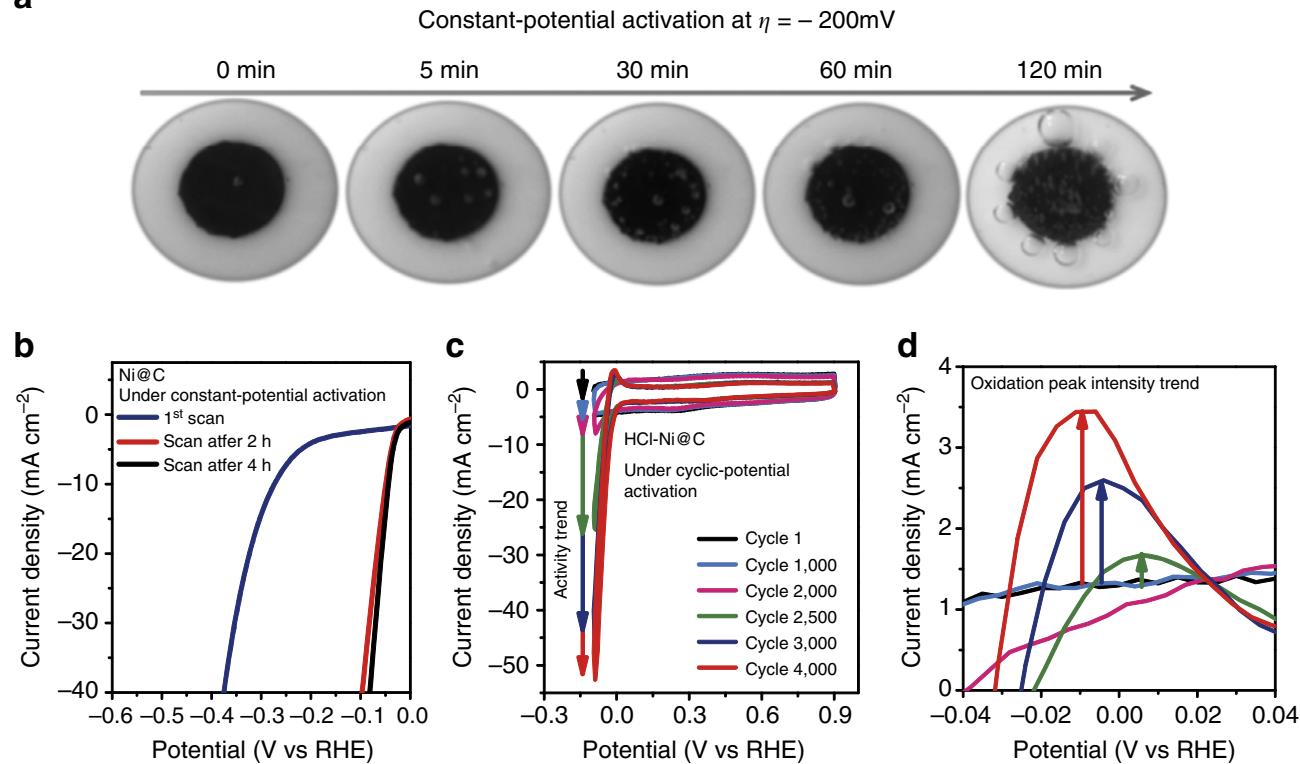

Figure 6 | Activation processes of the Ni-C catalysts. (a) Hydrogen bubbles driven at $\eta=-100 \mathrm{mV}$ at GC electrodes with different degrees of activation (constant-potential activation at $\eta=-200 \mathrm{mV}$ for different time). All the digital photos were taken when the cell turned on for $20 \mathrm{~s}$. The diameter of glassy carbon electrode is $5 \mathrm{~mm}$. (b) Initial and post-constant-potential activation LSV curves of Ni@C. The applied constant potential would activate Ni@C catalyst. (c) Cyclic voltammograms of HCl-Ni@C (cycle 1, cycle 1,000, cycle 2,000, cycle 2,500, cycle 3,000 and cycle 4,000 were selected). Catalytic activity trend corresponds to the improving current density. (d) Oxidation peaks of the catalyst in different cycles. The oxidation peak intensity increased and the peak potentials shifted in the negative direction in the anodic-going scan.

cycles). Furthermore, we did the galvanostatic electrolysis test to collect the evolved hydrogen gas to evaluate the Faradaic efficiency of the A-Ni-C catalyst. In Supplementary Fig. 9, the result demonstrates that A-Ni-C gives about $100 \%$ Faradaic yield during the electrolysis process. Overall, the high catalytic activity and outstanding durability illustrate the potential of $\mathrm{A}-\mathrm{Ni}-\mathrm{C}$ for 
cost-effective electrocatalytic hydrogen evolution in water electrolysis system and solar-driven hydrogen system.

Activation processes. Activation processes (constant-potential activation and cyclic-potential activation) were also recorded to investigate changes after activation. Hydrogen bubbles generated at $\eta=-100 \mathrm{mV}$ on Ni@C-decorated GC electrodes with different degrees of activation (Fig. 6a). Constant potential at $\eta$ of $-200 \mathrm{mV}$ (Supplementary Fig. 10) was used to stabilize the catalyst to reach the best performance, simultaneously ruling out the possibility that the high $j$ would result from the reaction between the unsecure $\mathrm{Ni}$ metal and the strongly acidic solution. The $j$ gradually improved in the first $2 \mathrm{~h}$ and levelled out in the next $2 \mathrm{~h}$. These activation treatments also ensured stable and reproducible results. LSV curves of Ni@C after different periods of constant-potential activation prove the activation process of Ni@C (Fig. 6b). During CV activation process, the catalytic $j$ of HCl-Ni@C gradually increased with the consecutive CV scans and reached the maximum efficiency after about 4,000 cycles (Fig. 6c). Notably, the anodic peaks around $0 \mathrm{~V}$ (versus RHE) shifted to lower potentials during the process, indicating a more easily occurring oxidation reaction. Interestingly, the oxidation peak intensities were also enhanced during the $\mathrm{CV}$ treatment (Fig. 6d). These signs during CV activation reveal that $\mathrm{A}-\mathrm{Ni}-\mathrm{C}$ could lose electrons more easily in the anodic-going scan. The oxidation peak intensity gradually levelled out when the cathodic catalytic $j$ nearly remained stable (Supplementary Fig. 11). These changes of the oxidation peak corresponding to valance changes of $\mathrm{Ni}$ coincide with the trend of the catalytic activity. In addition, we also collected the activated samples after different CV cycles for STEM analysis (Supplementary Figs 12 and 13). The downsizing of the $\mathrm{Ni}$ nanoparticles and the formation of single $\mathrm{Ni}$ atoms can be evident to be observed during the activation process. Throughout the detailed CV activation process, we summarize that active $\mathrm{Ni}$ single atoms would form during the activation process, leading to these changes of the oxidation peak and simultaneously contributing greatly to the improved activity. Furthermore, the HCl-Ni@C samples can also be activated on the fluorine-doped $\mathrm{SnO}_{2}$ (FTO) glass substrate (Supplementary Figs 14 and 15).

\section{Discussion}

In summary, we have used carbonization of MOFs to synthesize $\mathrm{Ni}-\mathrm{C}$-based catalyst and applied electrochemical potential to activate $\mathrm{Ni}-\mathrm{C}$ catalyst, which can reach outstanding performance during HER processes. The discovery of this $\mathrm{A}-\mathrm{Ni}-\mathrm{C}$ catalyst highlights a new area of tuning structure and functionality of metal-carbon-based catalyst at atomic scale by electrochemical methods, which would hold the promise for large-scale real-world water splitting electrolysers.

\section{Methods}

Chemicals. Nickel (II) carbonate basic hydrate (48-50\% Ni, Fluka), L-aspartic acid (98\%, Sigma-Aldrich), 4,4'-bipyridyl (98\%, Alfa Aesar), Nafion-117 solution (5 wt. \% in a mixture of lower aliphatic alcohols and water) (Sigma-Aldrich), sulphuric acid ( $98 \%$, Merck) and $\mathrm{HCl}(32 \%, \mathrm{RCI}$ labscan) were used as received without any further purification.

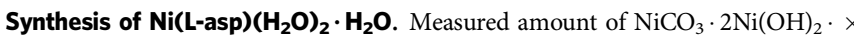
$\mathrm{H}_{2} \mathrm{O}(2.450 \mathrm{~g})$ and L-aspartic acid $(2.630 \mathrm{~g})$ were dissolved in water $(200 \mathrm{ml})$ under stirring and heating for $3 \mathrm{~h}$. After filtering out all the remaining solid particles, the clear turquoise solution was then evaporated at $80^{\circ} \mathrm{C}$ oven overnight to obtain the pale blue $\mathrm{Ni}(\mathrm{Asp})$ powder.

Synthesis of $\left[\mathbf{N i}_{2}\right.$ (L-asp) $\mathbf{2}_{2}$ (bpy) $] \cdot \mathbf{C H}_{\mathbf{3}} \mathbf{O H} \cdot \mathbf{H}_{\mathbf{2}} \mathbf{O}$ (Ni-MOF). $\mathrm{Ni}(\mathrm{L}-\mathrm{asp})\left(\mathrm{H}_{2} \mathrm{O}\right)_{2}$. $\mathrm{H}_{2} \mathrm{O}(0.219 \mathrm{~g})$ and $4,4^{\prime}$-bipyridyl $(0.312 \mathrm{~g})$ were dispersed in a mixture containing water $(6 \mathrm{~mL})$ and methanol $(4.742 \mathrm{~g})$ under ultrasonic vibration. The final solution was sealed into an autoclave and heated at $150^{\circ} \mathrm{C}$ for $48 \mathrm{~h}$. The product, $\left[\mathrm{Ni}_{2}(\mathrm{~L}-\right.$ asp) $)_{2}($ bpy $\left.)\right] \cdot \mathrm{CH}_{3} \mathrm{OH} \cdot \mathrm{H}_{2} \mathrm{O}$, was filtered, washed with copious amounts of water and methanol and dried at $60^{\circ} \mathrm{C}$ for $24 \mathrm{~h}$.

Carbonization of Ni-MOF. Carbonization processes were carried out in $\mathrm{N}_{2}$ atmosphere. The dried Ni-MOF powder was pretreated at $150^{\circ} \mathrm{C}$ for $2 \mathrm{~h}$ and then carbonized at different temperatures for $5 \mathrm{~h}$ with a heating rate of $5^{\circ} \mathrm{C} \mathrm{min}-1$

HCl leaching treatment. Excess concentrated $\mathrm{HCl}$ was slowly added into $\mathrm{Ni@C}$ hybrids and then the suspension was put under ultrasonic condition to dissolve $\mathrm{Ni}$ metal. The suspension was separated when being left to stand for $6 \mathrm{~h}$. The entire process was repeated two additional times. Then the product was washed with copious amount of water until the $\mathrm{pH}$ of the solution was $\sim 7$ and then dried at $60^{\circ} \mathrm{C}$ for $24 \mathrm{~h}$

Electrochemical measurements. All the electrochemical tests were performed in a conventional three-electrode system at an electrochemical station (CHI 660E), using $\mathrm{Ag} / \mathrm{AgCl}$ (3.5 $\mathrm{M} \mathrm{KCl}$ solution) electrode as the reference electrode, $\mathrm{Pt}$ mesh as the counter electrode and GC electrode as the working electrode. About $4 \mathrm{mg}$ of sample and $80 \mu \mathrm{l}$ of $5 \mathrm{wt} \%$ Nafion solution were dispersed in $1 \mathrm{ml}$ of $4: 1 \mathrm{v} / \mathrm{v}$ water/ ethanol by at least 30 -min sonication to form a homogeneous solution. Then $5 \mu \mathrm{l}$ or $15 \mu \mathrm{l}$ of the solution was loaded onto the GC electrode of $3 \mathrm{~mm}$ or $5 \mathrm{~mm}$ in diameter, respectively. The final loading for all catalysts and commercial $\mathrm{Pt} / \mathrm{C}$ electrocatalysts on the GC electrodes is about $0.283 \mathrm{mg} \mathrm{cm}^{-2}$. Similar preparation of titanium foil electrode was conducted with the same loading of the HCl-Ni@C samples and corresponding chronoamperometric curves of $\mathrm{A}-\mathrm{Ni}-\mathrm{C}$ was shown in Supplementary Fig. 16. LSV with scan rate of $5 \mathrm{mV} \mathrm{s}^{-1}$ was conducted in $0.5 \mathrm{M}$ $\mathrm{H}_{2} \mathrm{SO}_{4}$ deaerated with argon at room temperature. The $\mathrm{Ag} / \mathrm{AgCl} / 3.5 \mathrm{M} \mathrm{KCl}$ reference electrode was calibrated with respect to RHE. The calibration was performed in the high purity hydrogen saturated electrolyte with Pt mesh as the working electrode and counter electrode. CVs were run at a scan rate of $1 \mathrm{mV} \mathrm{s}^{-1}$, and the average of the two potentials at which the current crossed zero was taken to be the thermodynamic potential for the hydrogen electrode reactions (Supplementary Fig. 17). In $0.5 \mathrm{M} \mathrm{H}_{2} \mathrm{SO}_{4}, E_{\mathrm{RHE}}=E_{\mathrm{Ag} / \mathrm{AgCl}}+0.209 \mathrm{~V}$. AC impedance measurements were carried out in the same configuration when the working electrode was biased at the overpotential of $100 \mathrm{mV}$ from $10^{5} \mathrm{~Hz}$ to $10^{-1} \mathrm{~Hz}$ with an AC voltage of $5 \mathrm{mV}$. The CV measurements were performed by use of the scan rate at $100 \mathrm{mV} \mathrm{s}^{-1}$ between $+905 \mathrm{mV}$ and $-95 \mathrm{mV}$ (versus RHE) without accounting for uncompensated resistance. Chronoamperometric measurement $(\eta=-45 \mathrm{mV})$ was performed to evaluate the long-term stability. The faradaic yield was calculated from the total amount of electrons passed through the cell during the galvanostatic electrolysis and the amount of the evolved $\mathrm{H}_{2}$ gas collected by the water drainage method. The theoretically expected amount of $\mathrm{H}_{2}$ was calculated by applying the Faraday law, which states that the passage of $96485.4 \mathrm{C}$ causes 1 equiv. of reaction. The HER performance mentioned above was well reproducible in our laboratory. More than $10 \mathrm{~A}-\mathrm{Ni}-\mathrm{C}$-decorated GC electrodes (after CV activation) were evaluated, giving similar activation phenomenon and negligible difference of HER performance.

Characterization. XRD patterns were acquired at room temperature using D/MAX 2550 VB/PC. Raman spectrum was recorded on a Rennishaw InVia spectrometer with a model 100 Ramascope optical fibre instrument. XPS data were collected from ESCALAB 250Xi, and the binding energy of the C $1 \mathrm{~s}$ peak at $284.8 \mathrm{eV}$ was taken as an internal reference. TEM images were collected from TECNAI F-30 with an acceleration voltage of $300 \mathrm{kV}$. Subångström resolution STEM images were obtained on a JEM-ARM200F STEM fitted with a double aberration-corrector for both probe-forming and the imaging lenses.

\section{References}

1. Walter, M. G. et al. Solar water splitting cells. Chem. Rev. 110, 6446-6473 (2010).

2. Cook, T. R. et al. Solar energy supply and storage for the legacy and nonlegacy worlds. Chem. Rev. 110, 6474-6502 (2010)

3. Armaroli, N. \& Balzani, V. The hydrogen issue. ChemSusChem 4, 21-36 (2011)

4. U.S. Energy Information Administration. The impact of increased use of hydrogen on petroleum consumption and carbon dioxide emissions, http://www.eia.gov/oiaf/servicerpt/hydro/appendixc.html (2008).

5. U.S. Department of Energy Hydrogen Analysis Resource Center. Hydrogen Production, Worldwide Refinery Hydrogen, Production Capacities http:// hydrogen.pnl.gov/cocoon/morf/hydrogen/article/706 (2012).

6. Carmo, M., Fritz, D. L., Mergel, J. \& Stolten, D. A comprehensive review on PEM water electrolysis. Int. J. Hydrogen Energy 38, 4901-4934 (2013).

7. Zou, X. \& Zhang, Y. Noble metal-free hydrogen evolution catalysts for water splitting. Chem. Soc. Rev. 44, 5148-5180 (2015).

8. Jaramillo, T. F. et al. Identification of active edge sites for electrochemical $\mathrm{H}_{2}$ evolution from $\mathrm{MoS}_{2}$ nanocatalysts. Science 317, 100-102 (2007). 
9. Karunadasa, H. I. et al. A molecular $\mathrm{MoS}_{2}$ edge site mimic for catalytic hydrogen generation. Science 335, 698-702 (2012).

10. Chen, W.-F. et al. Hydrogen-evolution catalysts based on non-noble metal nickel-molybdenum nitride nanosheets. Angew. Chem. Int. Ed. 51, 6131-6135 (2012).

11. Cao, B., Veith, G. M., Neuefeind, J. C., Adzic, R. R. \& Khalifah, P. G. Mixed close packed cobalt molybdenum nitrides as non-noble metal electrocatalysts for the hydrogen evolution reaction. J. Am. Chem. Soc. 135, 19186-19192 (2013).

12. Vrubel, H. \& Hu, X. Molybdenum boride and carbide catalyze hydrogen evolution in both acidic and basic solutions. Angew. Chem. Int. Ed. 51, 12703-12706 (2012)

13. Xiao, P. et al. Novel molybdenum carbide-tungsten carbide composite nanowires and their electrochemical activation for efficient and stable hydrogen evolution. Adv. Funct. Mater. 25, 1520-1526 (2015).

14. Popczun, E. J. et al. Nanostructured nickel phosphide as an electrocatalyst for the hydrogen evolution reaction. J. Am. Chem. Soc. 135, 9267-9270 (2013).

15. Popczun, E. J., Read, C. G., Roske, C. W., Lewis, N. S. \& Schaak, R. E. Highly active electrocatalysis of the hydrogen evolution reaction by cobalt phosphide nanoparticles. Angew. Chem. Int. Ed. 53, 5427-5430 (2014).

16. Kibsgaard, J. \& Jaramillo, T. F. Molybdenum phosphosulfide: an active, acidstable, earth-abundant catalyst for the hydrogen evolution reaction. Angew. Chem. Int. Ed. 53, 14433-14437 (2014).

17. Callejas, J. F. et al. Electrocatalytic and photocatalytic hydrogen production from acidic and neutral-pH aqueous solutions using iron phosphide nanoparticles. ACS Nano 8, 11101-11107 (2014).

18. Zheng, Y. et al. Hydrogen evolution by a metal-free electrocatalyst. Nat. Commun. 5, 3783 (2014).

19. Ito, Y., Cong, W., Fujita, T., Tang, Z. \& Chen, M. High catalytic activity of nitrogen and sulfur co-doped nanoporous graphene in the hydrogen evolution reaction. Angew. Chem. Int. Ed. 54, 2131-2136 (2015).

20. Das, R. K. et al. Extraordinary hydrogen evolution and oxidation reaction activity from carbon nanotubes and graphitic carbons. ACS Nano 8, 8447-8456 (2014).

21. Voiry, D. et al. Enhanced catalytic activity in strained chemically exfoliated $\mathrm{WS}_{2}$ nanosheets for hydrogen evolution. Nat. Mater. 12, 850-855 (2013).

22. Kibsgaard, J., Chen, Z., Reinecke, B. N. \& Jaramillo, T. F. Engineering the surface structure of $\mathrm{MoS}_{2}$ to preferentially expose active edge sites for electrocatalysis. Nat. Mater. 11, 963-969 (2012).

23. Cheng, L. et al. Ultrathin $\mathrm{WS}_{2}$ nanoflakes as a high-performance electrocatalyst for the hydrogen evolution reaction. Angew. Chem. Int. Ed. 53, 7860-7863 (2014).

24. Li, Y. et al. $\mathrm{MoS}_{2}$ nanoparticles grown on graphene: an advanced catalyst for the hydrogen evolution reaction. J. Am. Chem. Soc. 131, 7296-7299 (2011).

25. Yang, J. et al. Two-dimensional hybrid nanosheets of tungsten disulfide and reduced graphene oxide as catalysts for enhanced hydrogen evolution. Angew. Chem. Int. Ed. 52, 13751-13754 (2013).

26. Li, D. J. et al. Molybdenum sulfide/N-doped CNT forest hybrid catalysts for highperformance hydrogen evolution reaction. Nano Lett. 14, 1228-1233 (2014).

27. Youn, D. H. et al. Highly active and stable hydrogen evolution electrocatalysts based on molybdenum compounds on carbon nanotube-graphene hybrid support. ACS Nano 8, 5164-5173 (2014).

28. Zou, X. et al. Cobalt-embedded nitrogen-rich carbon nanotubes efficiently catalyze hydrogen evolution reaction at all $\mathrm{pH}$ values. Angew. Chem. Int. Ed. 53, 4372-4376 (2014).

29. Deng, J. et al. Highly active and durable non-precious-metal catalyst encapsulated in carbon nanotubes for hydrogen evolution reaction. Energy Environ. Sci. 7, 1919-1923 (2014).

30. Deng, J., Ren, P., Deng, D. \& Bao, X. Enhanced electron penetration through an ultrathin graphene layer for highly efficient catalysis of the hydrogen evolution reaction. Angew. Chem. Int. Ed. 54, 2100-2104 (2015).

31. Vajda, S. et al. Subnanometre platinum clusters as highly active and selective catalysts for the oxidative dehydrogenation of propane. Nat. Mater. 8, 213-216 (2009).
32. Lei, Y. et al. Increased silver activity for direct propylene epoxidation via subnanometer size effects. Science 328, 224-228 (2010).

33. Qiao, B. et al. Single-atom catalysis of $\mathrm{CO}$ oxidation using $\mathrm{Pt}_{1} / \mathrm{FeO}_{\mathrm{x}}$. Nat. Chem 3, 634-641 (2011).

34. Kyriakou, G. et al. Isolated metal atom geometries as a strategy for selective heterogeneous hydrogenations. Science 335, 1209-1212 (2012).

35. Yang, M. et al. Catalytically active $\mathrm{Au}-\mathrm{O}(\mathrm{OH})_{\mathrm{x}}$-species stabilized by alkali ions on zeolites and mesoporous oxides. Science 346, 1498-1501 (2014).

36. Hall, D. E. Electrodes for alkaline water electrolysis. J. Electrochem. Soc. 128, 740-746 (1981).

37. Döner, A., Karc1, İ. \& Kardaş, G. Effect of C-felt supported Ni, Co and $\mathrm{NiCo}$ catalysts to produce hydrogen. Int. J. Hydrogen Energy 37, 9470-9476 (2012).

38. Xia, W. et al. Well-defined carbon polyhedrons prepared from nano metalorganic frameworks for oxygen reduction. J. Mater. Chem. A 2, 11606-11613 (2014).

39. Li, H. et al. XPS studies on surface electronic characteristics of Ni-B and Ni-P amorphous alloy and its correlation to their catalytic properties. Appl. Surf. Sci. 152, 25-34 (1999).

40. Manders, J. R. et al. Solution-processed nickel oxide hole transport layers in high efficiency polymer photovoltaic cells. Adv. Funct. Mater. 23, 2993-3001 (2013).

41. Du, J., Cheng, F., Wang, S., Zhang, T. \& Chen, J. M (Salen)-derived nitrogendoped $\mathrm{M} / \mathrm{C}(\mathrm{M}=\mathrm{Fe}, \mathrm{Co}, \mathrm{Ni})$ porous nanocomposites for electrocatalytic oxygen reduction. Sci. Rep. 4, 4386 (2014).

42. Tang, C., Cheng, N., Pu, Z., Xing, W. \& Sun, X. NiSe nanowire film supported on nickel foam: an efficient and stable 3D bifunctional electrode for full water splitting. Angew. Chem. Int. Ed. 54, 9351-9355 (2015).

43. Carpenter, M. K., Moylan, T. E., Kukreja, R. S., Atwan, M. H. \& Tessema, M. M Solvothermal synthesis of platinum alloy nanoparticles for oxygen reduction electrocatalysis. J. Am. Chem. Soc. 134, 8535-8542 (2012).

\section{Author contributions}

X.Y., S.Q. and H.G.Y. conceived the project and contributed to the design of the experiments and analysis of the data. L.F. and P.F.L. performed the catalyst preparation, characterizations and wrote the paper. Z.Z.Y. and L.G. conducted the STEM examination and contributed to writing the STEM section. L.F., P.F.L. and X.Y. collected the electrochemical data. All the authors discussed the results and commented on the manuscript.

\section{Additional information}

Supplementary Information accompanies this paper at http://www.nature.com/ naturecommunications

Competing financial interests: The authors declare no competing financial interests.

Reprints and permission information is available online at http://npg.nature.com/ reprintsandpermissions/

How to cite this article: Fan, L. et al. Atomically isolated nickel species anchored on graphitized carbon for efficient hydrogen evolution electrocatalysis. Nat. Commun. 7:10667 doi: 10.1038/ncomms10667 (2016)

This work is licensed under a Creative Commons Attribution 4.0 International License. The images or other third party material in this article are included in the article's Creative Commons license, unless indicated otherwise in the credit line; if the material is not included under the Creative Commons license, users will need to obtain permission from the license holder to reproduce the material. To view a copy of this license, visit http://creativecommons.org/licenses/by/4.0/ 